\title{
Representaç̃oes da organização familiar e comunitária dos teuto-brasileiros católicos do Rio Grande do Sul a partir da revista St.Paulus-Blatt (1912 a 1934)
}

Representations of family and community of german-brazilian catholics of Rio Grande do Sul in St.Paulus-Blattjournal (1912 to 1934)

Representaciones de la organización familiar y comunitaria de teuto-brasileños católicos de Rio Grande do Sul a partir de la revista St. Paulus-Blatt (1912-1934)

Samuel Klauck*

\section{Resumo}

$\mathrm{O}$ artigo busca compreender o papel da revista St. Paulus-Blatt como instrumento de informação e orientação e, em específico, contextualiza e analisa o destaque dado à mulher na organização cotidiana dos leitores teuto-brasileiros católicos dos espaços coloniais do Rio Grande do Sul. As análises delimitam-se ao período de 1912 a 1934, no qual o periódico foi editado e dirigido pelo sacerdote jesuíta Teodoro Amstad. Os conteúdos da revista são entendidos como discursos emanados do catolicismo da imigração, representado pelos jesuítas e pela Sociedade União Popular à qual o periódico se vincula. Infere-se que a linguagem e a tonalidade empregada em suas páginas procuram imprimir um imaginário coletivo e fixar uma visão de mundo a partir das suas representações.

Palavras-chave: Revista St. Paulus-Blatt. Teuto-brasileiros. Representações.

\footnotetext{
Doutor em História pela Universidade Federal do Paraná. Professor do Programa de Pós-Graduação em Sociedade, Cultura e Fronteiras, da Universidade Estadual do Oeste do Paraná. Membro do Grupo de Pesquisa Cultura, Fronteira e Desenvolvimento Regional.
}

Recebido em 28/06/2013 Aprovado em 05/07/2013 http://dx.doi.org/10.5335/hdtv.14n.1.4171 


\section{Introdução}

A presença de imigrantes alemães no Rio Grande do Sul é uma marca populacional importante na história do Estado. Esse contingente, em um processo de "enxamagem", segundo Roche (1969), espalhou-se pelas diversas regiões coloniais abertas, desde a primeira metade do século XIX. Como grupo estrangeiro em território nacional consolidaram uma identidade expressiva, construída, progressivamente nas relações sociais, culturais, políticas, econômicas e religiosas (CEM ANOS DE GERMANIDADE, 1999). Desse contexto, forma-se, a partir dos seus descendentes, um novo elemento identitário denominado comumente como teuto-brasileiro (WILLEMS, 1980, p. 169-189).

Dos espaços coloniais mães - da região de São Leopoldo, próximo a Porto Alegre, o grupo teuto-brasileiro, direciona-se e é direcionado - institucionalmente ou por ações imobiliárias -, ao planalto central, ao Norte e Noroeste do Rio Grande do Sul. Contudo, vale ressaltar que a suposta homogeneidade associada a esses imigrantes e migrantes esconde, segundo Emílio Willems (1980), questões nacionais, mas também religiosas (SCHALLENBERGER, 2001).

Dessas constatações introdutórias, delimita-se a abordagem em torno da assistência orientacional, oferecida pela revista St. Paulus-Blatt (Folha de São Paulo) a um contingente específico dessa população, nos anos em que o periódico foi editado e dirigido pelo sacerdote jesuíta Teodoro Amstad, de 1912 a 1934. O recorte temporal também compreende um período no qual os teuto-brasileiros alcançam e ocupam as novas re- giões coloniais, principalmente no Noroeste do Estado. Segue o objetivo de compreender o papel do periódico na orientação e instrução dos teuto-brasileiros nas regiões coloniais do Rio Grande do Sul. Em específico, contextualiza e analisa o destaque dado em suas páginas à mulher na organização cotidiana a partir das informações apresentadas.

Pode-se definir a revista como um dos instrumentos utilizados pelo catolicismo da imigração implantado pelos jesuítas entre os alemães e descendentes, desde a última metade do século XIX (LUTTERBECK, 1977; SILVA, 2003; SCHALLENBERGER, 2001; RAMBO, 2002), para acompanhar e ordenar os espaços sociais do segmento católico, integrantes desse contingente populacional. E, nesse contexto, os jesuítas também podem ser compreendidos como instrumentos da Igreja na organização prática do campo associativo e político. Pois, entre 1890 e 1912, esses, de forma direta, contribuíram para a fundação de seis associações: 1890, o Centro Católico; 1890, as Associações Paroquiais ou Pfarrvereine; 1898, os Congressos Católicos ou Katholikentage; 1898, a Associação de Professores ou Lehrerverein; 1890, a Associação de Agricultores ou Bauerverein; e, 1912, a Sociedade União Popular ou o Volksverein (RABUSKE, 1994/1996, p. 29).

Essa situação, destaca Erneldo Schallenberger, é marcada pelo enfrentamento de grandes problemas nas antigas colônias alemãs, associados, principalmente, ao excedente de população. Assim, o atendimento material volta-se à criação de novos núcleos de colonização; o social, à criação de entidades de ajuda financeira, hospitalar, técnica, comercial, etc.; e, o alento religioso associa- 
do à defesa da escola paroquial e do ensino religioso (SCHALLENBERGER, 2001, p. 305 et. seq.). Será o Volksverein que desempenhará grande parte dessas atribuições. A essência dos objetivos dessa associação resume-se em organizar os católicos de ascendência alemã em torno de uma sociedade que preconizasse o seu bem-estar social, material e religioso. Portanto, tal situação relacionada ao discurso inaugural da IX Assembleia Geral de 1912, ato da fundação da Sociedade (METZLER, 1912, p. 1-6), demonstra a mescla do discurso comunitário, representado pelos alemães e seus descendentes e do discurso religioso, que figura como produtor de sentido e organizador dos teuto-brasileiros católicos.

Essa situação permite perceber que um grupo expressivo da população do estado recebia atenção da Assembleia de 1912, com o intuito de estabelecer benefícios comuns. O grupo dos descendentes de alemães no Rio Grande do Sul, segundo estimativas de Jean Roche (1969, p. 169), nas primeiras décadas do século $\mathrm{XX}$, atingiam cifras em torno de $340.000^{1}$ mil pessoas, entre os quais, segundo dados da obra dos Cem Anos, quase a metade ${ }^{2}$ era de católicos (CEM ANOS, 1999, p. 556). Dentro desse contexto, entender a tentativa de associar toda essa população católica em torno de objetivos comuns (materiais, sociais e religiosos) representa uma ação abrangente da Igreja e não de instâncias laicas.

Do processo de atenção aos teuto-brasileiros, consolida-se a Sociedade União Popular no Rio Grande do Sul, que tem a revista St. Paulus-Blatt, publicada em língua alemã $\tilde{}^{3}$, como principal instrumento de comunicação impresso. Esse periódico de circulação abrangente entre os leitores católicos de língua alemã, com inserção em todas as regiões coloniais, cumpre segundo Samuel Klauck (2009), as funções de educar, formar e instruir/orientar a condução da vida cotidiana dos teuto-brasileiros. Segundo levantamento feito por Erneldo Schallenberger, em 1913 a Sociedade contava com 7.000 associados; em 1914, com 9.000; e, em 1934, havia aproximadamente 10.000 sócios espalhados por praticamente todo o estado do Rio Grande do Sul (SCHALLENBERGER, 2001, p. 316-400). Todo associado recebia a St. Paulus-Blatt, por isso é possível conjecturar que todos os sócios eram leitores da Revista. Além disso, o quadro de leitores incluía as famílias, formando, portanto, um panorama geral de leitores. ${ }^{4}$

A revista assume representatividade expressiva pelo aspecto de ser instrumento de informação, com diretrizes de formação, controlada e direcionada pelo viés do catolicismo da imigração, representado pelos jesuítas na figura do seu editor padre Teodoro Amstad, mas também, por sera ferramenta de organização cotidiana de um contingente expressivo de migrantes teuto-brasileiros nas regiões em que se fixaram. Cabe destacar que em diversos momentos esses aspectos apresentam-se intrinsecamente relacionados. Assim, a revista busca estabelecer ou fixar um imaginário social coletivo, que em uma acepção a Bronislaw Baczko

[...] torna-se inteligível e comunicável através da produção de "discursos" nos quais e pelos quais se efetiva a reunião de representações coletivas numa linguagem (BACZKO, 1985, p. 311). 
Dessa maneira, o papel orientacional da revista, compreendido sob o ponto de vista dos excertos de textos, são entendidos como discursos sociais e religiosos, que representam a tentativa de fixar uma visão de mundo a partir das representações neles expostas. Nessa perspectiva, os discursos do periódico, são compreendidos como representações que

[...] não são de forma alguma discursos neutros: produzem estratégias e práticas (sociais, escolares, políticas) que tendem a impor uma autoridade à custa de outros, por elas menosprezados, a legitimar um projeto reformador ou a justificar, para os próprios indivíduos, as suas escolhas e condutas. Para isso esta investigação sobre as representações supõe-nas como estando sempre colocadas num campo de concorrências e de competições cujos desafios se enunciam em termos de poder e de dominação. As lutas de representações têm tanta importância como as lutas econômicas para compreender os mecanismos pelos quais um grupo impõe, ou tenta impor, a sua concepção do mundo social, os valores que são os seus e o seu domínio (CHARTIER, 1990, p. 17).

A partir do autor, a imprensa, em específico a St. Paulus-Blatt, passa a ser compreendida, neste trabalho, como uma estratégia para alcançar a assistência orientacional aos leitores teuto-brasileiros nas suas respectivas regiões coloniais. Por sua vez, compreende-se que a utilização desse meio de comunicação perpassa o uso de uma linguagem autorizada, que é utilizada pela instituição e/ou por seus representantes, como portadora de autoridade simbólica dentro do campo religioso, capaz de forjar determinada visão de mundo.

Essa linguagem autorizada é legitimada a partir da posição social de quem a apre- senta. A sua utilização como forma de impor certa visão de mundo encontra consonância em Pierre Bourdieu. Para o autor "O uso da linguagem, ou melhor, tanto a maneira como a matéria do discurso, depende da posição social do locutor que, por sua vez, comanda o acesso que lhe abre à língua da instituição, à palavra oficial, ortodoxa, legítima" (BOURDIEU, 1996, p. 87). Enfoque que, na compreensão da revista St. Paulus-Blatt, é possível perceber o uso da linguagem como estratégia para afirmar uma determinada visão, defendida e propalada pela Igreja Católica, por meio de seus missionários, os jesuítas, representados pelo editor da revista.

Ainda, de acordo com essa assertiva, compreende-se que o efeito da linguagem ocorre somente a partir do reconhecimento das palavras e/ou discursos. Assim, a definição do sucesso desse jogo encontra equivalência na definição de eficácia simbólica que, segundo Pierre Bourdieu, é exercida somente

[...] na medida em que a pessoa-alvo reconhece quem a exerce como podendo exercê-la de direito, ou então, o que dá no mesmo, quando se esquece de si mesma ou se ignora, sujeitando-se a tal eficácia, como se estivesse contribuindo para fundá-la por conta do reconhecimento que lhe concede (BOURDIEU, 1996, p. 95).

Dessemodo, compõe-se o quadro que entende a revista como representante de um discurso vinculado à Igreja, que, dentre suas premissas, define uma visão de mundo nas representações e no imaginário social, buscandofixar-se entre os teuto-brasileiros católicos. A linguagem e os conteúdos assumem conotação de discurso performativo ao colocar-se como instrumento orientacional. Além disso, alcança legitimidade, pois é ba- 
lizada por um agente autorizado da Igreja Católica, por intermédio das ações e diretrizes da Sociedade União Popular. Essas definições introduzem as reflexões específicas que seguem.

Como indicado, o cotidiano familiar e comunitário das comunidades teuto-brasileiras católicas, nas regiões coloniais, recebia contribuições e orientações através do veículo de comunicação do Volksverein. Assim, essa Entidade pretendia alcançar os leitores através de informações úteis ao dia a dia dos sócios. Entre os destaques, a saúde ocupava espaço privilegiado nas edições da revista. A temática servia como instrumento prático e facilitador do cotidiano das comunidades congregadas à Sociedade. Evidências da preocupação com os assuntos relacionados à saúde são aferidas nos comerciais de médicos e de dentistas divulgados nas suas páginas. ${ }^{5}$ Tem-se, assim, a impressão de que havia atendimento médico e odontológico nas comunidades coloniais, contudo, a abrangência desses serviços, conforme expresso nos anúncios, era de consultórios localizados em Porto Alegre. A necessidade de tratamento especializado implicava deslocamento à capital do estado ou ao hospital de São Sebastião do Caí, mantido pela Sociedade União Popular. Dessa situação, conjectura-se que, para os eventuais problemas de saúde que se abatiam sobre as famílias em suas comunidades, eram encontradas alternativas, como a ingestão de medicamentos convencionais e caseiros, por exemplo.

Ao enfrentar essas e outras situações envolvendo cuidados com a saúde e com necessidades médicas, é possível perceber o papel orientacional que a revista representa aos leitores. Ela busca oferecer em suas páginas uma forma de medicina preventiva, divulgando procedimentos e conteúdos úteis a práticas do cotidiano. Além disso, a preocupação das matérias do periódico não assume característica de instrução pessoal, mas tem o intuito de reproduz em sua tonalidade a atenção com a família e com a comunidade. ${ }^{6}$

Contudo, o eixo central das análises concentra-se na reprodução dos princípios de orientação defendidos pela Sociedade União Popular. A preocupação com a saúde familiar e comunitária faz parte das questões assistenciais preconizadas pela Entidade. Nesse sentido, não se compreender as informações sobre a temática, dissociadas do contexto associativo e do envolvimento comunitário que reunia os católicos descendentes de imigrantes alemães no Rio Grande do Sul. Ao mesmo tempo, é possível conjecturar que a revista servia como instrumento de reprodução e de manutenção desses princípios e, em diversas situações, os seus conteúdos eram a saída encontrada pelos leitores para enfrentar eventualidades.

A questão da saúde dos leitores, no entanto, não deixa de estar relacionada à alimentação e aos cuidados com os alimentos. Referente a situação, aproximam-se as temáticas sanitárias e de diversificação alimentar promovidas pela revista. O periódico destacava comumente a problemática da saúde em forma de artigos. Uma das primeiras indicações e serve como indício dessa situação é a seção de textos intitulados Instruções sobre a manutenção da saúde e tratamento de doenças, assinados por H. Rüdiger de Porto Alegre (RÜDIGER, 1924, p. 9; RÜDIGER, 1925, p. 5). Mesmo sem indicação da formação do 
autor, pelo tom empregado apreende-se que há ligação direta com a área da saúde e/ou está devidamente inteirado com os assuntos. Nessas duas seções citadas, o autor destaca que na saúde nem sempre o que prevalece é a quantidade, mas sim a qualidade. Em síntese, orienta os leitores sobre a preocupação constante que se deve ter com o organismo, seja através da alimentação correta, dos cuidados de higiene e/ou da abstinência de hábitos nocivos, como por exemplo, o uso do fumo e/ou do álcool.

Essa abordagem, entretanto, nem sempre é destacada de forma isolada através de artigos. Já em fins da década de 1920, a revista começa a dar ênfase à problemática com a publicação de um quadro específico denominado Higiene - Gesundheitliches, a qual destaca-se questões sobre a vida sanitária relativa à saúde dos indivíduos. A diferença é que, a partir da implantação de um quadro específico sobre o tema, as questões relacionadas adquirem aspectos didáticos e organizativos. Assim, a manutenção do quadro permite aos leitores acompanharem dicas e incorporá-las, de forma progressiva, no seu cotidiano. Por sua vez, a revista passa a racionalizar o conteúdo orientativo de forma direcionada, abarcando a diversidade de questões encontradas entre a comunidade leitora. Ao mesmo tempo, a constante publicação desses excertos formará um manual e/ ou folhetos organizados, servindo para consultas e como guia prático para solução das questões correlacionadas.

Nesse contexto, evidencia-se que a saúde é tão importante quanto os aspectos produtivos, eno conjunto acabam por ter uma relação próxima à família e à comuni- dade. Tal questão é aferida, principalmente no quadro da revista intitulado Para as $\mathrm{Mu}$ lheres. $\mathrm{O}$ foco central dessa seção oferecia às mulheres um espaço feminino nas páginas da revista. E entre as muitas abordagens feitas nesse quadro, o conteúdo voltado à saúde destaca-se, permitindo compreender a relação que há com a questão familiar e comunitária dos leitores, pois na organização dos espaços de sociabilidade familiar colonial, cabia à mulher a vida doméstica, ainda que mantivesse contato paralelo com o cultivo do campo e no cuidado dos filhos. Dessa situação, predomina a ideia de que a organização do cotidiano e, sobretudo, a vida sanitária como a saúde e a higiene recaiam, principalmente sobre a mulher.

Assim, abordagens da St. Paulus-Blatt sobre como tratar doenças infantis (1927d, p. 10), os cuidados necessários para com os doentes (1927e, p. 5), cuidados com o preparo dos alimentos e a sua ingestão (janeiro de 1929, p. 5), cuidados sobre o excessivo consumo de banha (1929a, p. 9), entre tantos outros temas, eram destaque no quadro Para as Mulheres. De forma geral, nas temáticas indicadas é possível aferir que à mulher caberia grande carga de responsabilidade. Em primeiro lugar, caberia à mulher evitar problemas de saúde, como por exemplo, os decorrentes do consumo excessivo de banha, já que ela tinha o ofício de cozinhar. Ao mesmo tempo, deveria zelar pelos cuidados higiênicos e sanitários da infância. Além disso, recaía a ela a preocupação constante, quando o lar era infestado por doenças como o vírus influenza ou a febre tifoide, em proteger os não infectados e tratar os que já padeciam com a doença. 
Dessas constatações, inferimos a importância que o quadro orientacional tinha na organização da vida prática dos leitores. E, como apontamos anteriormente, as informações eram, antes de tudo, instrumentos de prevenção, pois no aspecto pedagógico e didático as matérias serviam para preparar as leitoras a evitar problemas, ou quando estes se manifestassem dentro dos seus lares poderem dar o devido encaminhamento.

Outro reflexo de que a Sociedade União Popular procurava envolver e organizar o cotidiano comunitário dos leitores pode ser aprendido na deliberação do XII Congresso Católico de Novo Hamburgo, em 1926. Nesse evento, os delegados incentivaram a participação feminina dentro da Entidade (ST. PAULUS-BLATT, 1927a, p. 7). Ressalta-se que dentro do Volksverein a vida associativa destacava-se através da presença masculina. A liderança, o magistério, a vida prática rural e o espaço social eram definidos pelo papel do homem. Contudo, a propagação dos princípios da Ação Católica, valorizando a participação dos leigos em ações sociais de caráter religioso, estimulou a discussão a respeito do fortalecimento dos sentidos caritativos entre os sócios.

Se o cotidiano do leitor da St. Paulus-Blatt era marcado por questões que envolviam suas necessidades materiais, culturais e religiosas, o eixo prático fixava-se na manutenção de sua vida vinculada ao campo que, dentro do projeto de restauração católi$\mathrm{ca}$, inspirava-se no comunitarismo. Segundo Lucio Kreutz, esse privilegiava a

[...] interioridade na comunhão com os semelhantes. Apregoava-se um ideal comunitário onde as pretensões individuais se limitassem no interior do grande todo. A sociedade deveria ser harmônica, hierarquicamente centralizada (KREUTZ, 1991, p. 9).

Conforme destacado, a presença da mulher nas edições da revista começa com a publicação da seção Para as Mulheres. Mesmo assim, um envolvimento direto em ações práticas do cotidiano das comunidades não era evidenciado. No ano posterior à realização do XII Congresso Católico, a revista informa que os anseios dos congressistas estavam sendo inseridos com a implantação do Auxílio Feminino - Frauenhilfe. Em artigo publicado em três edições, apresenta que:

Nas últimas viagens dos dois secretários viajantes do Volksvereins em quase todas as seções associadas é apresentada também a divisão "Auxílio Feminino". Os objetivos gerais dessa nova organização dentro do Volksverein o próprio nome já diz: "Auxílio Feminino". Ao lado da atividade dos sócios masculinos do Volksverein também deverão no futuro, ainda mais do que se sucede até agora, também as mulheres serem atraídas para a cooperação no Volksverein (ST. PAULUS-BLATT, 1927a, p. 7, grifo do original).

É possível apreender a ressonância das decisões tomadas pela Entidade e a ênfase na implantação dessa nova organização. Ao mesmo tempo, reforça-se o argumento de que a presença masculina era expressiva, mas também a determinação de inserir, progressivamente, a mulher dentro da Sociedade. Se as atividades domésticas - família, educação, manutenção do lar, auxílio na produção rural, etc. - definem o perfil geral da esposa do sócio do Volksverein, o novo empreendimento, ao chamá-las à cooperação, instiga e promove a integração comunitária. 
A primeira edição do texto reforça aos leitores o que é a nova organização. Mas, cabe ressaltar, a proposta já havia sido difundida pelos delegados presentes no Congresso e pelas visitas dos secretários viajantes. Ao apresentá-la, o periódico passa a ser visto como sinônimo de fortalecimento, como interlocutor junto às pessoas que não tiveram acesso às informações, e ao mesmo tempo, como um instrumento de formação dos leitores. Nesse caso, a revista assume sua dupla definição: de formar e informar os católicos descendentes de alemães do Rio Grande do Sul.

Contudo, o papel da mulher na comunidade, dentro do novo quadro permite compreender os sentidos sociais, caritativos e religiosos, envolvendo a Frauenhilfe. De acordo com a segunda edição do artigo:

Sob a direção da chefe local deverão as sócias do Frauenhilfe primeiramente procurar saber em suas picadas, quais são as famílias necessitadas do lugar. Lá elas encontrarão famílias, que por doenças ou outros acidentes caíram na miséria. Junto de outras famílias é talvez o pai um alcoólatra ou jogador que tem assim a infelicidade de endividar sozinho, a família. Como também se vê ela é sempre uma família infeliz, que a ajuda dos próximos falta. --- Uma outra vez é um determinado acidente, uma morte repentina, um incêndio infeliz, um devastador fenômeno natural, uma inundação ou temporal de granizo, a razão porque em uma localidade uma ou mais famílias se encontram em dificuldades (ST. PAULUS-BLATT, 1927b, p. 7, grifos do original).

A nova organização incentiva às mulheres a envolverem-se coletivamente com a comunidade na qualestão inseridas. O primeiro papel a ser desempenhado pelas sócias - de reconhecer a realidade cotidiana - evi- dencia a sua inserção dentro do espaço em que outrora os homens eram majoritários. Identificar pontos e/ou famílias em situação de vulnerabilidadedemonstra o envolvimento social do programa do Volksverein. Oferecer "tudo a todos" - lema do Volksverein, mesmo sob os aspectos caritativos, é sinônimo do envolvimento dos sócios e das sócias na resolução dos problemas locais. Esses préstimos comunitários encontram seus equivalentes em indicações bíblicas. Na forma proposta, os sentidos práticos, religiosos e sociais convergem para o sentimento comunitário, por isso, perceber a necessidade das famílias faz com que os valores conjuntos do "nós" católico, da Igreja e dos Sócios voltem-se à realidade e ofereçam respostas.

$\mathrm{O}$ excerto permite compreender que a ajuda, nos casos citados, envolvia demandas financeiras e/ou materiais. Mas não são somente esses que a nova organização procura estimular. Indica-se que:

Ao mesmo tempo, não é preciso frequentes auxílios financeiros diretos, muitas vezes não empregados outrora; Serviços caridosos pessoais geralmente realizam muito mais. Assim, por exemplo, poderiam as sócias da Frauenhilfe tomar parte disso em seus locais, para assumir determinados trabalhos domésticos de uma pobre parturiente, onde uma assumirá o consertar, outras o lavar, a terceira cuida das crianças e presta outros serviços caridosos à ela. Ou a gente assume junto de doentes graves a vigília alternada, o que em muitos abate, é um incalculável serviço de caridade (ST. PAULUS-BLATT, 1927b, p. 7, grifo do original).

Esse modo de ajudar também favorece o envolvimento comunitário, expressando valores de unidade, em que as pretensões individuais desaparecem. Além disso, a si- 
tuação mostra-nos o esforço em reproduzir e manter presente o sentido do nós entre os leitores. O ser caridoso está em consonância com o sentido de amor ao próximo. Nas duas situações, esse princípio sobressai. As definições adotadas no Volksverein reforçam o discurso social do modelo de catolicismo instaurado pelos jesuítas e o projeto de restauração católica no Rio Grande do Sul.

Através dos trabalhos que a Frauenhilfe poderia realizar, o artigo indica dois caminhos. O primeiro, envolve as sócias em suas localidades, as quais poderiam seguir o exemplo das colônias italianas, e em casos de doenças ou acidentes na família, as outras de alguma forma a ajudam nos serviços domésticos e nas atividades do cultivo ou da colheita (ST. PAULUS-BLATT, 1927b, p. 7). Ao mesmo tempo lembra que:

Outro trabalho não menos importante da Frauenhilfe seria a organização de uma escola para ensinar os trabalhos domésticos na forma mais simples. Em cada picada certamente tem mulheres ou moças que no cozinhar, no trabalho de alfaiate, no remendar, na administração do governo doméstico, no serviço com doentes, entendem um pouco mais que no geral as mulheres e moças da colônia (ST. PAULUS-BLATT, 1927b, p. 7, grifo do original).

Juntamente aos auxílios práticos às famílias necessitadas, na terceira edição do artigo, encontra-se as atividades e/ou compromissos das sócias com todos os sócios. Destaca-se, sobretudo, o papel caritativo voltado à coleta de recursos para empreendimentos que atendessem a todos os leitores. Enfatiza-se que "já esta primeira missão da formação de parteiras ocupará a Frauenhilfe por algum tempo" (ST. PAU-
LUS-BLATT, 1927c, p. 7). Aqui se perceber a preocupação da Entidade em auxiliar a parturiente nas suas localidades ou mesmo na implantação de centros especializados. A coleta de donativos era realizada para preparar as mulheres que atenderiam às necessidades das famílias, evitando problemas para mães e filhos na hora do parto. A contribuição da organização objetivava suprir as deficiências das regiões coloniais e, ao mesmo tempo, era uma resposta, via organização comunitária, à ausência do estado na prestação desses serviços.

A preocupação com a manutenção do hospital e do asilo mantidos pelo Volksverein em São Sebastião do Caí também fez parte da missão caritativa da Frauenhilfe. Segundo o artigo, "Também aí pode e deve a Frauenhilfe coatuar nesse empreendimento para garanti-lo e formá-lo. Antigamente, as coletas anuais dos sócios do Volksverein e Sociedades beneficentes eram realizadas sob a direção do secretário viajante" (ST. PAULUS-BLATT, 1927c, p. 7). Observa-se que a sociedade, além de envolver as mulheres no importante papel de manutenção da instituição, representando uma conquista coletiva, também significava a transferência de responsabilidade, já que as lideranças secretários viajantes deixariam de desempenhar tal papel. Issoinicialmente garantia um respaldo positivo junto às populações, uma vez que a contribuição adquiria sentido de "boa obra" para com o próximo. Ao mesmo tempo, promovia um envolvimento coletivo nas ações caritativas do Volksverein.

Como resultado dessa ação, além de formar parteiras e manter o hospital e o asilo, o texto também informa que "A gente tenciona 
mesmo, no transcorrer do tempo, também instalar um estabelecimento para surdos, para aleijados e imbecís " (ST. PAULUS-BLATT, 1927c, p. 7, grifos do autor). Além disso, informa-se que "o previsto asilo dos leprosos fará parte, dentro desta esfera de atividades, da Frauenhilfe" (ST. PAULUS-BLATT, 1927c, p. 7, grifos do original). Os excertos inferem o papel e o compromisso comunitário que as informações orientacionais assumiam. Informar aos leitores a respeito dos empreendimentos pleiteados, mostrando sua importância e estimulando-os a participar como agentes ativos desse processo, atendia aos anseios propostos nos princípios do Volksverein.

Com isso, conclui-se que, direta ou indiretamente, a revista St. Paulus-Blatt era instrumento de orientação e informação, podendo ser considerada como ferramenta de reprodução e fixação de representações propostas pelo catolicismo da imigração defendidas pelas ações missionárias jesuíticas e pela Volksverein. Contudo, a ênfase ao papel da imprensa é compreendida em um contexto, no qual os agentes-alvo, os teuto-brasileiros católicos, enquanto migrantes, estavam sendo inseridos e fixados em novas regiões coloniais. Isso significa que a revista supre ou procura ocupar o espaço, muitas vezes, vago, ou em disputa, sobre as visões de mundo, presentes nas diversas representações laicas que rondavam o cotidiano dessas populações.

Ao mesmo tempo, nota-se que ao expor nas suas páginas um conteúdo de caráter prático, organizacional e funcional, direcionados a atender as necessidades iminentes das populações, o faz em tonalidade performativa e através de um discurso reconhecido, emanado, de acordo com Bourdieu (1996, p. 89), de porta-vozes autorizados e legitimados dentro da comunidade, quais sejam a Igreja Católica, os jesuítas e as lideranças sociais. Essa conclusão permite conjecturar a grande capacidade de inserção e ressonância desses conteúdos entre os leitores e as comunidades de teuto-brasileiros. Nessa mesma perspectiva, destaca-se que a revista, coloca-se como promotora e detentora desssas representações, por si só, contribui na formação de comunidades imaginadas, as quais já existiam de fato, a partir da associação à Sociedade União Popular, encontravam reforço no periódico.

Por sua vez, na abordagem específica, conclui-se que a revista, ao investir esforços na informação e orientação feminina, não somente reproduz nova postura social-religiosa, que valoriza os leigos nas ações políticas, filantrópicas e assistenciais, mas procura, de acordo com a premissa de ferramenta orientacional, fixar representações, além de inserir o público feminino como coorganizador do cotidiano das regiões coloniais. Assim, os conteúdos acerca da higiene, saúde, alimentação, formação e assistência, cumprem o papel de objetivar um imaginário social, presente tanto nas premissas do catolicismo da imigração, representados pelos jesuítas, bem como o exposto pelo Volksverein.

\section{Abstract}

This article seeks to understand the role of the journal St. Paulus-Blatt as a tool to gather information and guidance and, in particular, it contextualizes and analyzes the emphasis on women in the organization of everyday life of German-Brazilian Catholic readers in colonies of Rio Grande do Sul. The analyses were delimited 
to the period 1912-1934, in which the journal was edited and directed by the Jesuit priest Teodoro Amstad. The tables of contents of the journal are understood as discourses emanated from Catholic immigration represented by the Jesuits and by the association called Society People's Union which binds the journal. It is inferred that the language and tone used in the journal pages try to represent a collective imaginary and set a world view from these representations.

Keywords: St. Paulus-Blatt journal. German-Brazilian people. Representations.

\section{Resumen}

El artículo busca comprender el papel de la revista St. Paulus-Blatt como instrumento de información y orientación y, en específico, contextualiza y analiza el destaque dado a la mujer en la organización de la vida cotidiana de los lectores teuto-brasileños católicos de los espacios coloniales de Rio Grande do Sul. Las analices se delimitan al período de 1912 a 1934, en el que el periódico fue editado y dirigido por el sacerdote jesuita Teodoro Amstad. Los contenidos de la revista son entendidos como discursos emanados del catolicismo de la inmigración, representado por los jesuitas y por la Sociedad União Popular a la cual el periódico es vinculado. Se infiere que el lenguaje y la tonalidad utilizadas en sus páginas buscan imprimir un imaginario colectivo y fija una visión de mundo a partir de sus representaciones.

Palabras clave: Revista St. Paulus-Blatt. Teuto-brasileños. Representaciones.

\section{Notas}

1 Segundo dados apresentados pelo autor, o Rio Grande do Sul possuía 1.149.070 habitantes em 1900 e, 2.182.713 habitantes, em 1920 (p. 224).

2 Os dados são um tanto quanto imprecisos. Para Amstad, no seu discurso na IX Assembleia Geral dos Católicos em 1912, cita que havia cerca de 100.000 colonos católicos alemães no Rio Grande do Sul (AMSTAD, 1912, p. 10).

3 As citações da revistano decorrer do texto em língua portuguesa foram traduzidas pelo autor.

4 Segundo Arthur Blásio Rambo, os alemães e seus descendentes criaram, desde a última década do século XIX, uma rede escolar comunitária, pela qual, praticamente todas as crianças - meninos e meninas eram alfabetizadas (RAMBO, 1994, p. 124). Essa informação corrobora a premissa que o quadro de leitores além dos sócios, incluía, plausivelmente, todos os seus familiares.

5 Os anúncios de serviços de médicos e de dentistas são distribuídos com frequência nas edições da revista a partir da segunda metade da década de 1920. Destaca-se, sobretudo, a ênfase na especialidade dos serviços e no domínio da língua alemã. Contudo, geralmente, os serviços eram oferecidos em centros próximos a Porto Alegre, distantes das novas regiões coloniais do Noroeste do estado.

6 Um exemplo dessa situação pode ser apreendido da reprodução do artigo intitulado A família e seus doentes, em vernáculo, extraído do $\mathrm{Al}$ manaque da Cáritas para o ano de 1928. Nesse texto, a autora que assina como enfermeira do bem-estar, destaca a atenção que se deve ter no cuidado e no tratamento dos doentes em leito familiar (RUCHWICH, 1927, p. 2).

\section{Referências}

AMSTAD, T. Wie gründen wir einen Volksverein für die deutschen Katholiken. In: Rio Grande do Sul? ST. PAULUS-BLATT. Porto Alegre, n. 1, 1912. p. 6-11.

BACZKO, B. Imaginação Social. In: Enciclopédia Enaudi. Lisboa: Imprensa Nacional/Casa da Moeda, 1985, v. 5, p. 296-332. 
BOURDIEU, P. A economia das trocas lingüísticas. São Paulo: Edusp, 1996.

CEM ANOS DE GERMANIDADE NO RIO GRANDE DO SUL - 1824-1924. Trad. de Arthur Blasio Rambo. São Leopoldo: Unisinos, 1999.

CHARTIER, R. História Cultural: entre práticas e representações. Rio de Janeiro: Beltrand Brasil; Lisboa: Difel, 1990.

KREUTZ, L. O professor paroquial - magistério e imigração alemã. Porto Alegre: UFRGS; Florianópolis: UFSC; Caxias do Sul: EDUCS, 1991.

KLAUCK, S. O apostolado da imprensa: a revista St. Paulus-blatt como instrumento de informação, formação e catequese no Rio Grande do Sul (1912-1934). 2009. Tese (Doutorado em História) - Universidade Federal do Paraná. Curitiba, 2009.

LUTTERBECK, Pe. J. A., S. J. Os Jesuítas no Sul do Brasil: capítulos de história da missão e província sul-brasileira da companhia de Jesus. São Leopoldo: Instituto Anchietano de Pesquisas, 1977.

METZLER, H. Die kulturellen Interessen der Deutschen Katholiken in Rio Grande do Sul. ST. PAULUS-BLATT. Porto Alegre, n. 1, 1912, p. 1-6.

RABUSKE, Pe. A., S. J. Antigas paróquias dos jesuítas no Brasil Meridional. Pesquisas - história. São Leopoldo, n. 29, p. 9-229, 1994-1996.

RAMBO, A. B. A escola comunitária teuto-brasileira. São Leopoldo: Unisinos, 1994.

Restauração católica no Sul do Brasil. História questões e debates. Curitiba, n. 36. 2002, p. 279-304.

ROCHE, J. Colonização alemã no Rio Grande do Sul. Porto Alegre: Ed. Globo, 1969.

RUCHWICH, M. Die Familie und Ihre Kranken. ST. PAULUS-BLATT. Porto Alegre, n. 10, out. 1927e. p. 2.
RÜDIGER, H. Belehrendes über Erhaltung der Gesundheit und Heilung von Krankheiten. ST. PAULUS-BLATT. Porto Alegre, n. 5, maio 1924, p. 9.

. Belehrendes über Erhaltung der Gesundheit und Heilung von Krankheiten. ST. PAULUS-BLATT. Porto Alegre, n. 2, fev. 1925, p. 5.

SCHALLENBERGER, E. O associativismo cristão no sul do Brasil: a contribuição da Sociedade União Popular e da Liga da Uniões Coloniais para a organização e o desenvolvimento social sul-brasileiro. 2001. Tese (Doutorado em História) - Pontifícia Universidade Católica do Rio Grande do Sul. Porto Alegre, 2001.

SILVA, N. S. T. da. A compreensão jesuítica da identidade (étnica) teuto-brasileira católica rural no Rio Grande do Sul: instrumento (de poder) do projeto de restauração católica regional (18721961). 2003. Tese (Doutorado em História) Centro de Ciências Humanas, Universidade do Vale do Rio dos Sinos. 2003.

ST. PAULUS-BLATT. Die Frauenhilfe im Volksverein. Porto Alegre, n. 2, fev. 1927a, p. 7 . Die Frauenhilfe im Volksverein. Porto Alegre, n. 3, mar. 1927b, p. 7.

. Die Frauenhilfe im Volksverein. Porto Alegre, n. 4, abr. 1927c, p. 7.

. Für die Frauen. Porto Alegre, n. 1, jan. 1929, p. 5.

. Krankenpflege. 1. Ungang mit Kranken. Porto Alegre, n. 10, out. 1927e, p. 5.

. Leichtsinnige Berschwendung bei den Speisen. Porto Alegre, n. 9, set. 1929a, p. 9.

. Ratschläge für Frauen. Kinder-Krankheiten. Porto Alegre, n. 5. maio 1927d, p. 10.

WILLEMS, E. A aculturação dos alemães no Brasil. 2. ed. São Paulo: Nacional, 1980. 